\title{
Corrigendum: Integrating Behavioral Theories in Agent-Based Models for Agricultural Drought Risk Assessments
}

\author{
Teun Schrieks ${ }^{1 *}$, W. J. Wouter Botzen ${ }^{1,2,3}$, Marthe Wens ${ }^{1}$, Toon Haer ${ }^{1}$ and \\ Jeroen C. J. H. Aerts ${ }^{1}$ \\ ${ }^{1}$ Institute for Environmental Studies (IVM), Vrije Universiteit Amsterdam, Amsterdam, Netherlands, ${ }^{2}$ Utrecht University School \\ of Economics (U.S.E.), Utrecht University, Utrecht, Netherlands, ${ }^{3}$ Risk Management and Decision Processes Center, The \\ Wharton School, University of Pennsylvania, Philadelphia, PA, United States
}

Keywords: agent-based model (ABM), drought risk assessment, behavioral theory, adaptation behavior, human decision-making, smallholder farmer

\section{A Corrigendum on}

\section{OPEN ACCESS}

Edited and reviewed by:

Heidi Kreibich,

German Research Centre for Geosciences, Helmholtz Centre

Potsdam, Germany

*Correspondence:

Teun Schrieks

teun.schrieks@vu.nl

Specialty section:

This article was submitted to Water and Human Systems,

a section of the journal

Frontiers in Water

Received: 05 October 2021 Accepted: 08 November 2021 Published: 24 November 2021

Citation: Schrieks T, Botzen WJW, Wens M,

Haer T and Aerts JCJH (2021) Corrigendum: Integrating Behavioral Theories in Agent-Based Models for

Agricultural Drought Risk Assessments. Front. Water 3:789702. doi: 10.3389/frwa.2021.789702
Integrating Behavioral Theories in Agent-Based Models for Agricultural Drought Risk Assessments

Schrieks, T., Botzen, W. J. W., Wens, M., Haer. T., and Aerts, J. C. J. H. (2021). Front. Water 3:686329. doi: 10.3389/frwa.2021.686329

In the original article, there was an error. In equation (3) in section Behavioral Theories, Expected Utility Theory, the discount factor in the budget constraint was presented as $\frac{1}{(1-r)^{t}}$. The standard formula for the discount factor is however $\frac{1}{(1+r)^{t}}$. The minus in the original article should be a plus.

A correction has been made to Behavioral Theories, Expected Utility Theory, paragraph 3 , Equation 3:

$$
C_{m, 0} \leq \sum_{t=0}^{T} \frac{1}{(1+r)^{t}}\left(W_{t}-\sum_{i=1}^{I} p_{i} R_{i, m, t}\right)
$$

The authors apologize for this error and state that this does not change the scientific conclusions of the article in any way. The original article has been updated.

Publisher's Note: All claims expressed in this article are solely those of the authors and do not necessarily represent those of their affiliated organizations, or those of the publisher, the editors and the reviewers. Any product that may be evaluated in this article, or claim that may be made by its manufacturer, is not guaranteed or endorsed by the publisher.

Copyright () 2021 Schrieks, Botzen, Wens, Haer and Aerts. This is an open-access article distributed under the terms of the Creative Commons Attribution License (CC BY). The use, distribution or reproduction in other forums is permitted, provided the original author(s) and the copyright owner(s) are credited and that the original publication in this journal is cited, in accordance with accepted academic practice. No use, distribution or reproduction is permitted which does not comply with these terms. 